\title{
UMA SALA DE AULA NA PROPOSTA DE ENSINO MODULAR : ESPAÇO A SER RETOMADO ${ }^{1}$
}

\section{Resumo}

Objetivo do presente estudo foi o de investigar e analisar alguns aspectos do ensino de Língua Portuguesa em uma escola que adota o Sistema de Ensino Modular, considerando o reflexo desse sistema no trabalho em sala de aula. Para tanto, acompanhamos duas classes de $5^{\text {a }}$ série, localizadas em duas escolas públicas do Estado de São Paulo ( uma Modular e outra Regular ), utilizando os seguintes instrumentos metodológicos: observação em sala de aula, questionários respondidos pelo corpo discente e docente e entrevistas com alunos da Escola Modular. Os dados foram analisados em função das categorias que foram se constituindo ao longo das observações em sala de aula : interação professor/aluno, organização do trabalho docente, relação do professor e do aluno com o conhecimento, tendo em vista a linguagem como mediação e como processo de ação que é social. Da análise, podemos afirmar que: 1) A qualidade da interação social que se estabeleceu nas classes observadas dependeu mais das concepções de linguagem/conhecimento assumidas pelas professoras, do que de uma mudança na estrutura da escola. 2) Os resultados mais satisfatórios no processo de ensino foram observados no trabalho que a professora da Escola Regular desenvolveu em sala de aula, ou seja, sua formação, sua experiência e seu compromisso é que determinaram. 3) Os projetos pedagógicos apresentados pelas escolas não foram construídos coletivamente. Embora existam projetos documentados, não foi possível estabelecer relações entre documentos e as ações desenvolvidas pelas professoras observadas. 4) Os alunos da Escola Modular referem-se às vantagens desse sistema, em termos da possível facilitação decorrente do fato de terem de cursar apenas uma disciplina durante o período letivo, sem pouparem críticas ao cansaço entediante que vem marcando as aulas. Assumem, entretanto, as responsabilidades pelos seus fracassos. A pesquisa aponta, também, a necessidade de se repensar a implantação de projetos pedagógicos construídos fora dos contextos em que serão implementados.

\section{Abstract}

The present study has the objective of investigating and analyzing some aspects of the Portuguese teaching in a school which adopt the Modular System of Teaching, by considering the effects of this system on the classroom work. For this aim, we have accomplished two classrooms of fifth grade, located in two public schools of State of Saint Paul (one modular and one regular) by utilizing the follow methodological instruments: observation in classroom, questionnaires for being responded by teachers and students and interviews with modular school students The data were analyzed in accordance with categories that were established as long as observations in classroom were carried.on: teacher-student interactions, docent working organization, relationship between teacher and student and knowledge, by taking the language as mediation and as a social acting process. From this analysis, we can to affirm that (1) the quality of social interaction which was established in the classrooms observed, relied more of lan-

\footnotetext{
*Mestre em Educação - Área de Didática. Especialista em Educação e Saúde Pública. Professora das Faculdades Integradas "Campos Salles".
}

1 Esse trabalho é baseado na dissertação de mestrado orientada pela professora-doutora Mary Júlia Martins Dietzsch e apresentada à USP em1997. 
guage/knowledge conceptions undertook by the teachers than a school structure changes. (2) The more satisfactory issues for the teaching process were observed in the work that the teacher of public school regular classroom has developed or what its formation , its experience, and its commitment have determined. (3) the pedagogical projects presented by schools weren't a collective construction. Although documented projects exist, it wasn't possible to establish relationship between documents and the actions developed by teachers observed.(4) The students from modular school see the advantages of this system as a possible facilitator derived from the fact that they take just one discipline through the course, criticizing the tireless in the classroom lessons. As well they assume, besides, the responsibility for their fails. The research appoints the need for thinking once more the implantation of pedagogical projects construed outside the context where they will be improvemented.

\section{Introdução}

Interessada em conhecer e pesquisar propostas educacionais que se diferenciavam pela sua eficácia ou pelas novas formas de pensar a educação, deparei-me com o Ensino Modular. Essa proposta me chamou atenção tanto pela novidade da idéia, quanto por suas características polêmicas.

O Sistema Modular de Ensino caracteriza-se, sobretudo, pela concentração das atividades inerentes a cada matéria da grade curricular durante seis horas por dia e por variável número de dias, de acordo com as cargas horárias previstas para cada campo disciplinar.

Diferente do Ensino Regular que trabalha todas as disciplinas simultaneamente, no "Sistema Modular Ensino Intensivo e Excludente" (SMË) cada disciplina é trabalhada de forma individual (uma por vez), por um período de tempo que atende às exigências de sua carga horária anual. No caso, por exemplo, de Língua Portuguesa, a carga horária de uma determinada série poderá ser concentrada num período de trinta e dois (32) dias com seis (6) horas/aula por dia. Uma vez cumprida a carga horária dessa disciplina, a classe passará a ter aulas de outra matéria do currículo, como Ciências, Geografia, Matemática, sempre uma por vez, não existindo um critério já estabelecido na seqüência da disciplina a ser ministrada. Essa seqüência fica atrelada às necessidades administrativas da escola. Os módulos são as disciplinas constantes na grade curricular, sendo ministrados, de forma intensiva e excludente, durante determinado número de dias.

Um dos aspectos considerados relevantes por aqueles que defendem a proposta Modular é o fato de não haver mais reprovações por série. $\mathrm{O}$ aluno que não for aprovado em determinado módulo, não precisará refazer a série. Poderá cursar a série subseqüente e fazer o módulo simultâneo, ou seja, aquele em que ficou retido. Conforme afirma Santos: "No Sistema Modular, os problemas específicos dos alunos não mais interferem na sua escolaridade. As reprovações nas séries estão zeradas, isto é, nenhum aluno fica na mesma série."

(...) "A reprovação nas séries é um "luxo" que sobrecarrega em $75 \%$ o orçamento da Educação. É um gasto desnecessário que poderia ser aplicado em: melhores salários, informatização das salas de aulas, diminuição do número de alunos nas classes, na melhoria geral dos recursos e na qualidade do ensino."(SANTOS, 1994, p.15)

Outro aspecto considerado positivo pelos defensores da proposta Modular é o de haver uma redução do abandono e da evasão escolar, pois o fato de o aluno não ficar reprovado na série, mas apenas no módulo, incentiva a sua permanência. É, ainda, Santos(1994) quem menciona:

"A redução em $80 \%$ dos casos de evasão e abandono escolar é marco tão fantástico, que, por si só, justificaria a existência do Sistema Modular de Ensino". (p.22)

No contexto da sala de aula, a qualidade de ensino também é evidenciada pelos seguidores da proposta Modular. As interações sociais seriam mais adequadas, efetivas, permitindo e estimulando o diálogo. "O estreitamento das relações 
entre alunos e professores fez com que, de repente, cada um passasse a ter um nome e não fosse conhecido apenas pelo número da matrícula ou por um detalhe físico mais significativo."(SANTOS, 1994, p.20.)

Nessa linha de considerações, vale ressaltar que tais afirmações são apenas expressas, ou seja, não existe um texto explicativo ou uma experiência que comprove essas colocações. Porém, tais perspectivas deixaram-me muito entusiasmada: diminuição de repetência, redução da evasão escolar, economia de verbas destinadas à educação. Sem dúvida, valeria a pena investigar melhor essa proposta.

A partir dos estudos realizados ${ }^{2}$, decidi investigar alguns tópicos relacionados ao processo de ensino de Língua Portuguesa em uma escola que adota o Sistema Modular de Ensino, partindo das seguintes questões:

1.Será que o fato de o Ensino Modular concentrar um tempo maior nas relações interpessoais em sala de aula garantiria que as aulas fossem mais eficientes em termos de aprendizagem?

2.Até que ponto a montagem curricular em módulos disciplinares intensivos e excludentes poderia estar modificando a articulação entre as várias áreas de conhecimento e influindo na organização do trabalho pedagógico na escola?

3.Um dos aspectos que me chamou a atenção foi a forma como uma proposta "nova" pode ser percebida pelos alunos. Geralmente, quando estamos diante de algo considerado inovador, pensamos ou até assumimos que "terá que dar certo". Nesse sentido, a terceira pergunta envolvia a relação dos alunos com o conhecimento, na presente proposta.

Para possibilitar a compreensão dessas questões, acompanhei uma escola estruturada em módulos, observando mais especificamente o módulo de Português, na 5a. série. Simultaneamente, para uma análise comparativa e mais aprofundada, investiguei uma Escola Regular, ou seja, que não atua dentro da proposta modular. A observação desenvolvida nas duas salas de aula se apoiava, inicialmente, em estudos realizados por Vygotsky $(1994,1995)$ e outros autores, como Nóvoa(1991,1992,1995), Martins(1996) e Calkins(1989), que discutem, respectivamente, a importância das relações sociais na construção do conhecimento, a organização do trabalho na escola e o ensino de Língua Portuguesa. No presente trabalho, pretendo ressaltar a primeira questão. Minha intenção é analisar alguns aspectos de ensino de Língua Portuguesa em uma escola que adota o Sistema Modular de Ensino.

Partimos de uma concepção de linguagem entendida como forma de interação. Mais do que um instrumento de comunicação e de expressão de pensamento, a linguagem é percebida aqui como um lugar de interação humana, construída socialmente e marcada pelo seu caráter interlocutivo. Nessa concepção, a linguagem não é percebida, simplesmente, como um código para transmitir informações ou uma forma de exteriorizar o pensamento. Quando utilizamos a linguagem, estamos interagindo, atuando sobre o outro, influenciando-o e sendo influenciados. A comunicação é percebida como um processo no qual as pessoas envolvidas procuram negociar sentidos, tentando criar significados partilhados. Não é só "passar" informações, mas compartilhálas. Assim, a linguagem é a possibilidade de interação comunicativa buscando a produção e construção de significados, de sentidos, enfim, de elaboração de conhecimento.

Pelo exposto, pensamos que o ensino da língua começa pela construção de relações adequadas, que permitirão uma efetiva interação entre o professor e os alunos; cada um tem seu espaço para se colocar, participar, dialogar, negociar, enfim, constituir-se como sujeito.

${ }^{2}$ Estou me referindo ao relatório realizado pela CENP intitulado "Estudo avaliatório das unidades escolares da Rede Estadual de Ensino com organização didático-pedagógica estruturada em módulos" e ao estudo realizado pela professora Sueli Tenca denominado "O ensino através de módulos na Escola Padrão João XXIII - estudo e acompanhamento de um projeto em implantação”/CEI-1994. 


\section{O trabalho empírico: condições e} procedimentos de investigação

O primeiro critério de escolha das escolas estava relacionado ao fato de uma ser "Modular" e a outra "Regular". Além disso, era importante que ambas estivessem situadas no mesmo município e que houvesse aceitação do trabalho pela direção e pelas professoras envolvidas.

$\mathrm{O}$ estudo aqui exposto foi realizado durante o ano letivo de 1995, quando acompanhei o cotidiano de duas salas de aula (5a.série); uma inserida na proposta Modular aqui denominada escola "X" ${ }^{3}$ e outra na Convencional, que será denominada "Y". Além desse acompanhamento, fiquei também atenta às situações que envolviam o todo da escola. Assim, participei de reuniões pedagógicas, reuniões de pais, conversei com a direção, com funcionários e alunos.

A opção pela escolha das classes observadas se justifica: de um lado, por estar interessada em analisar aspectos do ensino modular relacionados com o ensino de Língua Portuguesa e, de outro, por ser esse o menor nível de ensino (5a. série) atuando dentro dessa proposta, pois as classes de 1a a 4a séries trabalham com um único professor. Outro aspecto determinante foi o fato de as professoras mostrarem-se solícitas e até interessadas, dispostas a colaborar.

A classe observada na escola "X" era composta de quarenta e três (43) alunos, na faixa etária de 11 a 17 anos, havendo dois alunos que estavam fazendo o módulo simultâneo. A sala de aula observada da Escola "Y" era composta de 29 alunos na faixa etária de 11 a 17 anos.

Após os primeiros contatos, fui para as salas de aula. Não utilizei nenhum instrumento, gravador ou vídeo, visto que, segundo as professoras, isso lhes causaria inibição. Como forma de registrar os dados, utilizei a escrita e, ao iniciar cada registro, indiquei o dia, a hora e o local da observação. Um caderno foi utilizado para registrar os eventos. Procurei também não chamar muito a atenção dos alunos e das professoras para essas anotações. Vale assinalar que os registros desses dados incluíram não só os fatos referentes às situações observadas, mas também as reflexões e impressões próprias da pesquisadora.

\section{Alguns episódios : Ensino de Língua Portuguesa}

\subsection{Escola "X" - Ensino Modular}

Acompanhei quase todo o módulo de Língua Portuguesa, tendo feito um total de (104) cento e quatro horas de observação. Durante a permanência na sala de aula, posicionei-me de tal forma que me fosse possível conversar e interagir com os alunos, sempre preocupada em não prejudicar os trabalhos desenvolvidos. Em quase todos os eventos registrados e observados, os alunos estavam sentados um ao lado do outro, em filas verticais, virados para a frente. Somente numa aula observei uma disposição diferente, com os alunos reunidos em grupos para a execução de um trabalho (com o jornal).

Praticamente, todas as atividades realizadas pelos alunos se restringiram ao uso do livro didático, e os textos impressos serviram tanto para leitura, como para exercícios de compreensão e de gramática. A professora, praticamente, seguia sempre o mesmo ritual, ou seja, leitura silenciosa, leitura em voz alta pela professora e por alguns alunos, e exercícios propostos no livro, como ilustra o episódio seguinte:

A professora entregou à classe o livro didático de português; porém, muitos alunos não o receberam, pois não o haviam pago.

Profa. : "Quem está sem o livro é para sentar com o colega... O primeiro tema do livro é a "Origem", o segundo texto "Origem dos brasileiros", a formação étnica. O terceiro texto fala sobre a formação do povo brasileiro com a mistura de outros povos... É para fazer a leitura silenciosa ..."

Depois da leitura silenciosa, a professora fê-la em voz alta e comentou o texto.

Profa. : "Eu vou sortear alguns números para

${ }^{3}$ Como é de praxe em casos semelhantes, o nome da escola e os das pessoas que lá trabalham e estudam foram substituídos por outros, fictícios, a fim de manter em sigilo suas identidades. 
fazer a leitura ... número 10 faça a leitura. Quando o colega lê, os outros ficam em silêncio."

Aluno: Fez a leitura.

Profa. :"n.12 continue, jovem, fale alto."

Aluno: Fez a leitura.

Profa. : "Pode parar, no8 continue a leitura."

Aluno: Fez a leitura.

Profa. : "Vamos passar para o segundo texto. É para fazer leitura silenciosa."

A professora agiu da mesma forma; fizeram a leitura silenciosa e a seguir em voz alta; pequeno comentário sobre o texto e o sorteio de alguns alunos para leitura.

Observei, desde o início, que os procedimentos utilizados pela professora eram rotineiros e, apesar de todas essas atividades, o clima era bastante tumultuado e inúmeras vezes a professora solicitava silêncio. $\mathrm{O}$ episódio transcrito a seguir reforça essa afirmação:

Profa.: ..."Eu quero com isso que vocês aprendam a ter gosto pela leitura, a ter prazer com a leitura ... Nós vamos começar o segundo tema do nosso livro que é a "Família"... Fazer a leitura silenciosa das páginas 16 e $17 . "$

Após a leitura, a professora comentou:

"No dia de visitar o pai, duas crianças, filhos de pais separados, conversam sobre suas dificuldades para se adaptarem às mudanças na família."

Imediatamente, interrompe com o seu próprio comentário, em tom de ameaça:

"Quem não tem o livro é para as mães virem conversar comigo...; quem não tem livro é para sentar com o colega e não é para esquecer o livro em casa... Nesta primeira prova, eu não fiz "pegadinha"; na segunda prova, eu farei."

A professora retoma a leitura. Momentos depois, interrompe de novo e diz:

"Se, todas as vezes que tenho de parar, eu perco o sentido do texto..., o meu colega que está rindo é que lerá.".

Após a leitura realizada pelo aluno, a professora dirige-se novamente à classe:

"Questão n.1, quem pode responder ?... Quem gostaria de responder ?... Eu vou fazer chamada oral, vocês não estão participando... Olha pessoal, muita conversa... Vamos fazer silêncio... Meu amigo de vermelho, responda a questão n.1."

$\mathrm{O}$ aluno respondeu à questão e a professora fez um comentário. Não foi possível compreender o que foi dito pelo aluno nem pela professora, pois a classe "conversava" muito. Depois do comentário, a professora escreveu a resposta no quadro e pediu para os alunos a copiarem. $\mathrm{Na}$ seqüência do exercício, foram respondidas as demais questões, sempre dentro do mesmo procedimento, ou seja, aluno responde, professora comenta, escreve a resposta no quadro e os alunos copiam.

Continuando, a professora diz:

Profa.: "Vamos ler, o que nós vimos ontem nos textos das páginas 26 e 27? Do que se trata?"

Aluno: "Sei lá professora..."

Profa.: "Você aí, sentado no canto!"

Aluno: (fez alguns comentários, porém não foi possível escutar.)

A professora comentou o texto. Em seguida, escreveu na lousa as respostas referentes às questões de compreensão que estavam no livro. Posteriormente, pediu aos alunos que copiassem.

Profa.: "Agora que vocês copiaram, vamos passar para outro texto. Vamos fazer uma leitura silenciosa durante cinco (5') minutos."

Profa: "O que vocês entenderam do texto?"

Alunos: Muitas vozes.

A professora fez a leitura em voz alta, comentando em seguida.

Profa.: "Nós percebemos que esse texto é informativo..Alguém gostaria de fazer algum comentário, alguma pergunta?"

Aluno: "Não professora."

Profa.: "Vamos ler. Meu amigo Paulo, pode começar a leitura."

Após a leitura do texto, faz o seguinte comentário:

Profa.: "Vocês estão desinteressados; teremos critérios rigorosos para fazer os módulos simultâneos. Eu ouvi a leitura que vocês fizeram e pouquíssimos leram de forma adequada. Precisam prestar mais atenção... Vamos fazer a compreensão do texto que está na página $31 \ldots$ Vocês estão conversando muito, 
eu vou anotar os nomes dos alunos que estão bagunçando".

Diante do tumulto da aula, a professora escreve as respostas no quadro e pede para todos copiarem. A indisciplina observada parece ser um reflexo da desorganização da própria professora, das formas como abordava o texto: são apresentados fragmentos de textos retirados do livro didático, cabendo ao aluno apenas responder às questões do professor. Além disso, em seus comentários, estava mais preocupada em controlar a classe com ameaças do que com a interpretação do texto. Embora a professora se preocupasse com que os alunos tivessem gosto pela leitura, essa preocupação não ia além de sua fala. Em um dos poucos momentos em que os alunos foram convidados a participar e colaborar com a professora, percebia-se uma mudança na dinâmica da classe. $\mathrm{O}$ episódio a seguir ilustra o que ocorreu:

A professora fez a leitura de um texto e pediu aos alunos que informassem o assunto tratado.

Profa. : "Eu vou ler bem devagar e vocês vão descobrir o que é..."

Após a leitura, a professora fez a pergunta :

Profa. : "O que é?"

Crianças : "Árvore."

Profa.: "Quando vocês querem, vocês prestam atenção."

A professora fez a leitura de uma história.

Profa.: "Quem gostou da história? Vocês perceberam que este texto lembra a prosa, ele rima ... Eu vou continuar aproveitando este momento que vocês estão mais calmos e vou voltar à atividade anterior... Meu amigo Douglas, quais são suas principais características?"

A professora passa de carteira em carteira, fazendo perguntas e o diálogo fica restrito à professora e ao aluno. Não foi possível escutar o que estava sendo dito.

Esse momento me surpreendeu, pois em poucas ocasiões percebi o grupo interessado no que estava sendo proposto. Porém, o mais incrível foi a constatação da professora: ... "Eu vou continuar aproveitando este momento que vocês estão mais cal- mos e vou voltar à atividade anterior." Quando a professora conseguiu estabelecer um entrosamento melhor com o grupo, ela quebra e retoma atividades pelas quais os alunos já haviam demonstrado desinteresse.

Isso é algo muito presente no dia-a-dia de nossas salas de aula. A preocupação maior de alguns professores é cumprir um determinado programa, mesmo que o grupo já tenha, por diversas vezes, demonstrado que não está conseguindo acompanhar e que, por isso, não tem interesse, pois o que está sendo proposto não faz sentido algum para ele.

Enquanto observei a classe, não houve leitura de textos literários, embora tenha surgido uma proposta para que os alunos lessem algum livro pelo qual tivessem interesse, não presenciei quaisquer comentários das possíveis leituras realizadas pelos alunos. Investigando os livros lidos e discutidos no módulo de Português, fui informada pela professora de que: "Os livros não chegaram a ser discutidos, pois o objetivo proposto naquele momento era a descoberta do prazer pela leitura, sem cobranças da leitura integral."

A professora parece relacionar leitura com prazer, passando uma visão espontaneista desse trabalho. Porém, leitura é construir significados e, principalmente, é partilhar esses significados. No processo de busca do sentido do texto, é necessário compartilhar interpretações. Nesse aspecto, o papel do professor é fundamental, porque sendo ele um leitor mais experiente, poderia servir de mediador entre o texto e o aluno. Enquanto observadora, ficou difícil perceber quais eram os objetivos das atividades, ou seja, o que a professora pretendia com o que estava sendo proposto. Além desse aspecto, parecia não estar preocupada em relacionar os assuntos às aprendizagens anteriores e à realidade dos alunos. As informações eram passadas de forma fragmentada, o que dificultava a compreensão. Não havia espaço para novidades, outros caminhos e sugestões. Era tudo muito previsível. $\mathrm{O}$ processo de ensino estava completamente centrado na professora, cabendo aos 
alunos receberem, de forma passiva, o que estava sendo trabalhado. A professora trazia o conteúdo pronto e os alunos apenas se limitavam a "escutá-la", ficando a aula tumultuada, com indisciplina e desinteresse. $O$ que verifiquei foram "tentativas", por parte da professora, de se fazer escutar e de fazer os alunos prestarem atenção no que estava sendo dito, nem que para isso fosse usado instrumento de coerção. A professora falava o tempo todo, porém era uma fala sem um interlocutor definido; os alunos falavam também, mas, na maioria das vezes, entre eles.

As atividades de leitura e interpretação de texto, a prática de sala de aula não propiciava a interação entre professora e alunos. Em vez de um discurso que deveria ser construído coletivamente, tínhamos uma leitura, ora realizada silenciosamente, ora em voz alta, e a interpretação do texto permitida pela professora. Aquilo que o aluno havia entendido sobre o texto não era considerado, existindo somente uma versão autorizada do mesmo, que era feita pela professora. Sabemos que os momentos de conversação, de troca de impressões sobre o texto, possibilitam construir/reconstruir o sentido do texto. Contudo, nesses episódios não observamos tais atitudes. Tudo era preestabelecido e determinado, não existindo outras possibilidades, nem visões, nem idéias ou até outros sentidos. Apesar dos episódios serem diálogos, só detectamos monólogos, onde a professora passava a sua versão, a única autorizada e correta, sem contestação. Segundo Kleiman(1993), a escola tem possibilitado somente uma maneira de abordar o texto, permitindo uma única interpretação. Para a autora: "...é durante a interação que o leitor mais inexperiente compreende o texto: não é durante a leitura silenciosa, nem durante a leitura em voz alta, mas durante a conversa sobre aspectos relevantes do texto"(1993,p.24.).

Os alunos precisam saber que um texto pode ser lido de muitas maneiras, cabendo ao professor respeitar as possíveis leituras que surgirão na sala de aula.

Além dessas situações rotineiras, observei também algumas tentativas de ações que visavam atividades de linguagem. Coloquei como "tentativas", pois não verificamos o retorno dessas propostas. Nesse sentido, ressalto o seguinte episódio:

Profa. : "Vocês farão a leitura de qualquer coisa. Pode ser jornal, bula de remédio, receita, livro... Todo o dia eu vou sortear e a pessoa terá que comentar o que leu e se descobriu alguma palavra interessante. É para registrar a leitura e colocar a data, o título e observações."

A profa. escreveu no quadro a forma como a atividade deveria ser feita.
Data
Título
Observações
O que aprendeu
$\mathrm{O}$ que trouxe de bom

Com relação às atividades de escrita, foram realizadas poucas produções, não sendo feita nenhuma em sala de aula. Nas primeiras sessenta (60) horas de observação, apenas foi feita uma produção escrita, cujo tema proposto pela professora estava vinculado às leituras do livro didático. O tema proposto foi o seguinte: "Faça um texto contando sua origem. Esse texto deve permitir que o leitor conheça um pouco mais sobre você e sua família".

A realização da tarefa cumpriu mais uma determinação da seqüência apresentada no livro, do que um trabalho redigido pelos alunos. A redação foi realizada no caderno e, posteriormente, foi corrigida pela professora. Os alunos não tiveram a oportunidade de ler em classe seus escritos e os comentários ficaram restritos ao "olhar" da professora.

Uma outra proposta de escrita foi solicitada para ser realizada nas férias e foi colocada da seguinte forma, pela professora: "Após o recesso das nossas aulas, cada um deverá trazer o resumo de um livro lido, ou seja, contar a história como entendeu, oralmente e por escrito..."

Apesar do Sistema Modular possibilitar uma concentração maior de tempo nas relações interpessoais (6 horas-aula por dia), favorecendo ao professor a organização do espaço da sala de aula, não presenciei quaisquer tentativas de criar 
condições mais favoráveis para que a escrita acontecesse.

Uma constatação preocupante foi que, apesar do tempo mais flexível, de um espaço mais exclusivo e de se tratar do ensino de Língua Portuguesa, as produções escritas não aconteceram. A sala de aula não propiciou esse trabalho. Parece que o trabalho com escrita ficou restrito ao que era proposto no livro didático e, como este pouco propunha, a escrita não teve seu espaço. A escrita como palavra do aluno, como uma forma de sua expressão não se faz presente em sala de aula. Escrever é sinônimo de fazer cópia.

Praticamente, em todas as atividades de leitura e interpretação de texto, a professora utilizou o livro didático. O livro era composto, na sua maioria, por exercícios cujo objetivo era mais o de identificar, localizar ou completar determinada frase.

Apesar de ter sido, sistematicamente, lembrado pela professora que a gramática não deveria ser vista como uma regra a ser seguida, as atividades de gramática foram tratadas em sala de aula através de aulas expositivas e exercícios sobre determinado conceito; predominou o ensino de regras. Em alguns momentos, ela fez uso de outro livro didático, no sentido de ampliar as informações, mais especificamente dos conceitos de gramática.

Mesmo nas atividades relacionadas com a gramática, percebemos uma rotina na sua execução. Podemos observar isso, no seguinte episódio:

Profa. : "Ontem nós comentamos como se forma o adjetivo pátrio."

Aluno: "Pelo sufixo."

Profa. "É formado através de um substantivo próprio."

A professora escreve no quadro :

Roma - romano

Profa. : "Não é para ficar decorando."

A professora continua escrevendo outros exemplos no quadro :

Pará - paraense
Minas - mineiro

Profa. : "Vocês têm que saber porque ocorre. Se alguém chegar na rua e perguntar a vocês o que é adjetivo pátrio , como vocês podem responder?"

Aluno: Muitas vozes.

Profa. : "É importante compreender" porque acontece... Vamos corrigir a parte de linguagem, página 13."

A professora responde a questão número $1 \mathrm{e}$ faz um breve comentário.

Profa.: "Quem respondeu a segunda pergunta? ... Eu vou abaixar a nota, se vocês não responderem."

Aluno : Levantou a mão e respondeu: "Quem nasceu em Campos é campeiro."

(...)

Profa.: "Questão n.3 ... Como se chamam as pessoas que nascem nos Estados brasileiros?"

(...)

Profa:: "Eu vou fazer chamada oral, vocês não estão participando... Olha, pessoal, muita conversa..."

Os conceitos gramaticais trabalhados eram, primeiramente, escritos no quadro, lidos pela professora e, após essas atividades, passava para alguns exercícios constantes do livro didático ou exercícios transcritos no quadro. $\mathrm{O}$ modo como a gramática foi tratada e a composição dos a que foram submetidos os alunos mostram claramente que prevaleceram as atividades de memorização, onde o conteúdo era tratado de forma fragmentada, procurando levar os alunos à conceituação por meio da definição. $\bigcirc$ episódio a seguir esclarece:

Aluno: "É um substantivo professora."

Profa. : "Eu não quero ficar dando regras gramaticais, mas o adjetivo atribui qualidade ao substantivo... Não vou fazer assim, porque não quero que vocês decorem regras ... Eu quero que vocês escrevam correto..."

Profa. : "Quem não compreendeu?"

Aluno: "Eu não compreendi."

Profa. : "Também você não prestou atenção... Quem mais não compreendeu?"

(Silêncio) 
Profa:: "Eu não quero aluno guardando regra gramatical."

A professora voltou ao exemplo dado e explicou o que deve ser acrescido para formar o adjetivo pátrio.

Profa.: "Eu não quero que vocês fiquem aprendendo regra, mas que vocês saibam como e porquê as coisas ocorrem."

Apesar da professora afirmar que não era necessário decorar as regras gramaticais e até sugerir que o importante era compreender, quando ela depara com as respostas dos alunos, aparece a seguinte colocação: "Eu vou repetir tanto, que vocês aprenderão de tanto eu falar".

Procurando aprofundar essa questão, perguntei para a professora: $\bigcirc$ que você queria dizer quando citou em aula: "Eu não quero ficar dando regras gramaticais, mas o adjetivo atribui qualidades ao substantivo... Eu não quero aluno guardando regra gramatical..."

Segundo a professora:

"Lamentavelmente, na maioria dos livros didáticos, assim como nas próprias gramáticas e até nas Propostas Curriculares, sempre as definições são explicitadas em forma de regras, algumas bem técnicas. Por outro lado, aprendemos também nesse sistema. Portanto, procurei fugir um pouco, dar uma pequena pincelada em cima da visão sobre a regra do adjetivo, mas sempre relacionando o mesmo, que neste caso foi o "enfoque" com situações práticas."

Apesar da professora afirmar que não queria ensinar gramática através de regras e exercícios repetitivos, as observações em aula não demonstravam isso. A interferência da professora sugere uma visão negativa da gramática, possivelmente pautada em informações sobre as quais não teve oportunidade de refletir e assimilar. Assim, apenas "repetir" o que não deve ser feito já parece suficiente para torná-la membro de um grupo que considera "moderno", "avançado".

Outro aspecto que nos chamou a atenção diz respeito à forma como o erro poderia estar sendo tratado em sala de aula. Quando a professora diz: "Quero olhar o caderno de vocês, quero ver os erros de ortografia e a falta de atenção", o que está por trás dessa forma de olhar os erros dos alunos? Quais são as intenções da professora? Parece que a preocupação maior estava em evitar o erro, procurando punir quem o fizesse. Dentro dessa perspectiva, o erro não contribui para a construção do conhecimento e, inclusive, numa visão construtivista, o erro "é possível, ou até necessário, isto é, faz parte do processo.” (Lino,1994,p.69.)

Mais uma vez tentava controlar a classe com a punição. A interação estabelecida estava longe de ser mediada pelo conhecimento, sendo pautada mais no controle e punição. $\mathrm{O}$ episódio a seguir reforça essa afirmação:

Profa.: "...eu vou repetir tanto, que vocês aprenderão de tanto eu falar... Caio, quando eu uso "menas"?

Aluno : "Sei lá professora, eu estou fazendo lição."

Profa.: "Meu amigo Caio é repetente?"

Aluno: "De um módulo só."

Profa.: "Quando eu uso "menas"?"

Aluno: "Quando alguém tem menas coisa."

Aluno: "Não existe "menas".

Profa.: "Ah!, bom sinal que há alguém prestando atenção ... meu amigo Caio, não existe "menas", está prestando atenção e vocês estão desligados ... algumas pessoas estão com a cabeça longe ... quero olhar o caderno de vocês, quero ver os erros de ortografia e a falta de atenção."

○ trabalho realizado com a gramática não visava construção dos conceitos. A professora não criou possibilidades, para que os alunos pensassem. Inclusive, quando investiga os pensamentos de seus alunos, despreza o que foi dito e pressupõe que sua explicação foi mais que suficiente. A concepção de ensino-aprendizagem, presente em sala de aula, é pautada na função do professor que transmite e na do aluno que assimila, de forma idêntica, o que lhe está sendo "passado", sem restrições. As idéias prévias que os alunos têm sobre determinado assunto não são consideradas como suporte para novos conhecimentos. 
Praticamente, a professora domina todos os turnos de fala, ou seja, é ela quem determina as ações, as perguntas, as respostas, os procedimentos e as possibilidades. A professora é quem tem a palavra; geralmente suas perguntas são dirigidas ao grupo e as respostas freqüentemente induzidas. Apesar de todo esse "domínio", percebi que ela não conseguia estabelecer um trabalho conjunto, no qual os alunos pudessem ser coresponsáveis pelo seu processo de ensino. Registramos outras situações, porém não sentimos necessidade de reproduzi-las. Embora o professor permaneça numa mesma classe num período maior, não precisando mudar de turma a cada aula, percebemos, desde o início, que existe uma "rotina" nas relações professor/aluno, como se soubéssemos o que iria ser dito e respondido. Tudo parecia muito previsível, esperado. $\mathrm{O}$ que isso significa? Por que acontecia? Que tipo de relação foi sendo estabelecida?

Um dos pressupostos falsos levantados nessa proposta de Ensino Modular é afirmar que o fato do professor permanecer mais tempo com o seu grupo possibilitará vínculos mais sólidos e trocas mais efetivas. As relações que contribuem para o processo de ensino são difíceis de ser alcançadas. Elas não dependem só de condições físicas (tempo maior com o seu aluno). O fato do professor permitir o diálogo, deixar que os conhecimentos prévios que os alunos têm sobre determinado assunto venham à tona, necessita de outros fatores.

Corroborando com essa análise e acrescentando dados pertinentes, Delamont (1987) estuda as interações na sala de aula. Segundo a autora, a forma do professor perguntar já foi objeto de vários projetos de pesquisa. A autora ressalta o estudo realizado por Bellack (1966) que levantou quatro tipos de ação falada: estruturação, solicitação, resposta e reação. Os estudos verificaram que os papéis assumidos em sala de aula eram bem definidos, ou seja, os professores perguntavam e os alunos respondiam. Outro estudo evidenciado foi o de Barnes (1971), que analisou gravações de algumas aulas do primeiro ano de uma escola unificada. Este estudo demonstrou que o professor utiliza um grande número de perguntas "fatuais", ou seja, que procuram verificar o que os alunos sabem sobre um determinado assunto e, geralmente, os professores já conheciam as respostas que deveriam ser dadas. Perguntas abertas que procurassem investigar o que o aluno conhece sobre determinado tema não aconteceram. Fazendo um paralelo desses trabalhos com os episódios registrados, percebi que as perguntas formuladas pela professora situam-se nos estudos realizados, ou seja, a professora estabeleceu, desde o início, perguntas fatuais, destinadas a verificar o que os alunos sabiam sobre determinado assunto, porém as respostas já eram conhecidas por ela. Não percebi perguntas que buscassem informações novas sobre os temas trabalhados. Segundo Delamont, isso acontece em sala de aula, porém na vida cotidiana é considerado anormal.

"Sujeitar uma pessoa a repetidas perguntas sobre um assunto, tentar verificar o que ela sabe a seu respeito e praticar interrogatórios são coisas grosseiras na vida cotidiana, mas constituem a marca essencial da vida da sala de aula."(Delamont, 1987, p.139.)

Já discutimos anteriormente que, para uma determinada interação ser realmente educativa, necessita de algumas ponderações. Quando exponho esta idéia, estamos partindo do princípio de que a educação se dá nas interações professor/aluno e aluno/aluno, que são permeadas de intencionalidades e envolvidas por conteúdos escolares.

Analisando os episódios selecionados, podemos perceber que, nas atividades propostas, a linguagem era concebida como uma via de mão única, destituída de sua fluidez e de sua polissemia. Verifiquei que são poucos os momentos em que a professora permitiu a palavra ao aluno. A linguagem era transmitida por ela e acatada pelo aluno, sem restrições nem comentários, era usada para dar informações, quando os aspectos interpretativos eram deixados de lado. Apesar de termos registrado alguns diálogos, estes se carac- 
terizavam mais como monólogos. A professora com sua fala autoritária, a única que ditava a verdade, impedia o processo interlocutivo. Complementando essas informações, lembro uma afirmação de Citelli(1991): "O fato da linguagem ser dialógica não garante que a sua forma de apresentar-se abandone os esquemas de mando e dominação próprios do procedimento monológico... Se o professor pensa no ensino da língua a partir de uma referência interacional (inte/ração), saberá radicalizar o aspecto dialógico e trabalhará o seu discurso como um entre vários, no meio dos quais estarão aqueles dos alunos que vivem experiências culturais diferenciadas, que falam sobre o mundo a partir de lugares múltiplos, que operam variáveis lingüísticas nem sempre afinadas com o mestre" (p.16)

Nesse sentido, quando o professor pensa no ensino da língua, partindo de uma visão interativa, conseguirá respeitar os vários discursos na sua sala de aula e perceberá que sua fala é uma entre as várias que estão presentes no seu meio.

Além das atividades pouco significativas, chama a atenção a forma como a professora se dirige aos alunos. Em vez de serem chamados pelos nomes, os alunos são: "o número oito(8)", "o jovem", "você de vermelho", "meu amigo"... Como pode ser constatado, em muitas das situações observadas, seis horas - aula diárias de contato com a classe não seriam suficientes, para que fossem identificados pelos nomes. Não é esse um dos objetivos da Escola Modular?

"O estreitamento das relações entre alunos e professores fez com que, de repente, cada um passasse a ter um nome e não fosse conhecido apenas pelo número da matrícula ou por um detalhe físico mais significativo."(SANTOS, 1994, p.20.)

\section{2 - Escola "Y" - Ensino Regular}

Assim como nas aulas de Português da Escola Modular, os alunos do Ensino Regular também estavam sentados um ao lado do outro, em filas verticais, virados para a frente. Somente em alguns momentos tivemos uma disposição dife- rente, com os alunos em grupos, para a execução de uma atividade ou para dividirem seus materiais.

O modo de agir do professor poderá favorecer ou não o desenvolvimento dos alunos. Nas observações realizadas, percebemos que, nas atividades solicitadas, a professora procurou a participação dos alunos, incentivando-lhes a iniciativa.

As leituras realizadas em sala de aula não ficaram restritas aos textos presentes no livro didático. Com relação à abordagem dos textos, a professora usava a seguinte estratégia: primeiro uma leitura silenciosa, depois uma leitura em voz alta realizada por alguns alunos, simultaneamente à leitura o comentário do texto e, finalmente, contar a história que foi lida ou reescrevê-la.

As atividades de leitura, interpretação e produção de textos caminharam, em alguns momentos, de forma interligada, como pode ser visto nas situações que seguem:

A professora começa a aula retomando a leitura de um texto que estava impresso no livro didático. cio."

Profa. : "Vocês vão ler com os olhos, em silên-

Os alunos fazem a leitura.

Profa.: "Quem gostaria de participar, quem gostaria de ler?"

Alguns alunos levantam as mãos.

Profa: "Rodolfo, que bom que você levantou a mão, estou gostando de vê-lo participar. Faça a leitura, todos em silêncio."

Rodolfo inicia a leitura e, após terminar o primeiro parágrafo, a professora o interrompe, perguntando:

Profa:: "Quando você leu esse primeiro parágrafo, o que você lembrou? Ei, turma, a que texto podemos associar este trecho?"

Alunos: "Amor e ódio... Grande amor"

Profa. : "A história daquele cachorro que morreu de amor. Continue a leitura Rodolfo."

(...)

Profa: "Nós ficamos mais de três meses trabalhando com textos do nosso folclore. Vocês até fize- 
ram um trabalho escrito e cada grupo tinha que apresentar três lendas...Então, quem lembra quem era Potira?"

Alunos : "Uma india."

Profa. : "Quem é o outro personagem?"

Alunos: "Guerreiro."

(...)

Profa:: "Para onde Itajubá teve que ir ?"

Alunos: "Para a guerra."

Profa.: "O que é guerra para vocês?"

Alunos : Muitas vozes.

Profa.: "Um de cada vez, quero escutar todo mundo... Janaína, fale você... turma, vamos fazer silêncio para escutar Janaína falando..."

Janaína: "Um país vai atacar outro país."

Profa.: "Muito bem, que outra definição poderíamos ter... Quem gostaria de falar?"

Aluno: "A guerra da Alemanha e Israel."

Profa.: "A Segunda Guerra Mundial, que foi entre a Alemanha e os judeus. Como vocês imaginam que seja uma guerra?"

Alunos: Muitas vozes.

(...)

Profa.: "Quem gostaria de resumir oralmente o texto?"

Três alunos fizeram o resumo oralmente. Terminando, a professora colocou a seguinte questão:

Profa.: "Por que os três resumos estão certos?"

Alunos: Muitas vozes.

Profa.: "Nós já discutimos isso antes. O resumo é algo pessoal. Cada um entende de um jeito e tem sua forma de expressar a história... Agora, vamos criar uma ilustração para a história ?..."

As falas são muito ricas e mostram a interação estabelecida entre a professora e os alunos. Percebe-se, desde o início, que eles se mostraram atentos e interessados em participar.

A professora procurou trabalhar os mesmos assuntos de formas diferentes, destacando-se o fato de ter permitido diversas interpretações do texto e possibilitado uma reflexão sobre a leitura individual. Mostrou-se aberta a outras visões do texto, que não a sua própria ou a do autor, indicando sua idéia do texto como um espaço de significação a ser interpretado pelo leitor. As divergências eram reforçadas, sem conclusões antecipadas, sendo interessante ressaltar que, no pedido de silêncio, para ouvir a palavra do outro e a sua própria, o que está em jogo é a organização do trabalho para propiciar a interação e o conhecimento.

Outro aspecto no trabalho de leitura diz respeito à intertextualidade, uma vez que a professora procurou retomar outras leituras, outros textos já elaborados para o entendimento do que estava sendo lido. $\mathrm{Na}$ intertextualidade, o autor coloca, de forma clara ou não, uma outra voz em seu texto e o entendimento dessa apropriação textual e de importância para uma visão dialógica da leitura, carecendo de um espaço para ser trabalhado em classe.

Para as atividades a serem realizadas em casa, foi sugerida a leitura de dois textos literários, observando-se mais uma vez a preocupação da professora com a participação e envolvimento da classe com a leitura. Podemos observar isso, no seguinte episódio:

Profa.: "Eu trouxe este livro para vocês... foi falado hoje no terceiro colegial... "Ou isto ou aquilo", quem escreveu foi Cecília Meirelles. Eu vou ler algumas poesias para vocês."

A professora fez a leitura de alguns poemas.

Profa.: "Eu pedi que vocês fizessem a leitura de um livro e que contassem a história para os colegas aqui na classe. Francisco, o que você leu? Você disse que iria ler um conto de fadas ou uma fábula. O que você leu?"

Aluno: "Uma fábula."

Profa.: "O que é uma fábula?"

Aluno: "É uma história em que só participam animais."

Profa.: "Por quê?"

Aluno: "A raposa é esperta e cada animal representa as qualidades e os vícios."

Profa.: "Quem escreveu as primeiras fábulas?"

Aluno: Fez um comentário, porém não consegui escutar.

Profa.: "Nós já comentamos isso. O que é conto de fadas?" 
Aluno: "Histórias só para crianças."

Profa.: "Mas eu gosto de ler. Vocês também já leram lendas, fizeram teatro. Qual a diferença? O que é conto de fadas? O que é lenda?"

Aluno: "Lenda é uma história que vai passando de pai para filho. Os contos de fadas são contados para todas as crianças em todos os países."

Outro aluno: "Conta uma história que não existe...é um personagem criado pela imaginação."

Profa.: "Por que nós chamamos estas histórias de conto de fadas?"

Aluno: "Histórias que não existem."

Profa.: "Mas elas representam alguma coisa na nossa vida? Quais as mensagens que os contos querem transmitir? O que nós aprendemos com "A roupa nova do imperador"?"

Aluno: "Não podemos ser gananciosos, não devemos ser egoístas."

Profa.: "Muito bem, existe uma mensagem, existe um objetivo... Antes de começar, vamos saber as histórias que foram lidas e que serão contadas. Cada um fala a história que leu."

Os alunos falaram os títulos dos livros lidos: Robin Hood, A Bela Adormecida, João e Maria, A Princesa e a Ervilha, O Soldadinho de Chumbo, Pinóquio, Branca de Neve, Cinderela, Os três porquinhos, Peter Pan, Alice no país das maravilhas, A Bruxinha de minissaia, A espada era lei. Alguns alunos não leram e a professora sugeriu uma visita à biblioteca, no final da aula, para retirarem algum livro que quisessem ler. Na próxima aula, teriam que informar o que estavam lendo.

Profa:: "Cleber, conte sua história. Qual foi a história que você leu?"

Aluno: "Robin Hood. Eu não fiz o resumo escrito. Eu não terminei de ler."

Profa.: "Fale um pouco da sua história, do que você leu..."

Aluno: "Robin nasceu na Inglaterra..."

$\mathrm{O}$ aluno contou um pouco da história.

Profa:: "Vocês sabem onde fica a Inglaterra?"

Alunos: Muitas vozes.

Profa.: "Fica longe ... Outro país ... capital é Londres ... Qual a mensagem que você está tirando da história?"
Aluno: "Robin era uma pessoa boa. Tinha uma opção de vida diferente ... ele escolheu uma vida simples ... ele queria ajudar os pobres."

Profa.: "Quem gosta dessa história?"

Alunos: Muitas vozes.

Muito do que foi elaborado em sala de aula partiu da possibilidade de expressão da fala, tanto dos alunos quanto da professora. $\mathrm{O}$ diálogo era evidenciado e reforçada a partilha de opiniões, a professora buscando problematizar o que estava sendo pensado, dito, argumentado, através de questões que fizessem os alunos expressarem suas opiniões e que possibilitassem a discussão e complementação das idéias que circulavam no grupo. $O$ exemplo ilustra a importância da interação social na construção do conhecimento.

A atuação da professora ia muito além de uma contribuição espontânea, o seu papel sendo o de uma mediadora entre o texto e as idéias que foram surgindo. Foi ela quem coordenou as ações, buscando a participação de todos, incentivando quem se propusesse a falar, ou ajudando os alunos que permaneciam em silêncio.

Com relação à produção escrita, observei que uma das atividades mais utilizadas foi a escrita de histórias já lidas pela professora e discutidas com a classe. Embora a professora possibilitasse o trabalho em dupla, pudemos constatar que a maioria preferia realizar seu próprio texto individualmente. Para os livros lidos em casa, foi proposto um resumo oral, geralmente feito em classe, e um escrito, para ser entregue. $\mathrm{O}$ episódio selecionado ilustra essa questão:

A professora começa a aula retomando a leitura de um texto que estava impresso no livro didático. Após a leitura, sugere:

Profa.: "Quem gostaria de resumir oralmente o texto?"

Três alunos fizeram o resumo oral. Terminando, a professora colocou a seguinte questão:

Profa.: "Por que os três resumos estão certos?"

Alunos: Muitas vozes.

Profa.: "Nós já discutimos isso antes. O resumo 
é algo pessoal. Cada um entende de um jeito e tem sua forma de expressar a história... Agora vamos criar uma ilustração para a história ?..."

\section{(...)}

Profa.: "Quem acabou de ilustrar a história ... Pode escrevê-la...Contem por escrito a história que escutaram e que foi ilustrada por vocês. "

Apesar das oportunidades de escrita acontecerem de forma mais constante do que na Escola Modular, não presenciei discussões que visassem uma reelaboração do que havia sido escrito. A leitura dos textos cumpria mais a função de divulgar o trabalho do que de criar oportunidades para os alunos discutirem e repensarem o que havia sido escrito.

Como afirma Calkins(1989):

“(...)é essencial que as crianças estejam profundamente envolvidas com a escrita, que compartilhem seus textos com os outros e que percebam a si mesmas como autores. Creio que estas coisas estão interconectadas. Uma sensação de autoria nasce de uma luta para imprimir no papel algo grande e vital, e da observação de que as próprias palavras, impressas, atingem os corações e as mentes dos leitores." (p.22)

$O$ fato de haver muitos alunos sob sua responsabilidade e a falta de tempo para ler o que tem sido escrito foram apontados pela professora como obstáculos para um trabalho mais adequado com a escrita.

Diferentemente da sua colega da Escola Modular, essa professora procura trabalhar a gramática através de sua concepção de conhecimento e de linguagem. Nas atividades propostas, a discussão, a reflexão, as trocas acontecem. $\mathrm{O}$ episódio a seguir é esclarecedor:

Profa.: "Vamos sentar... Enquanto vocês estiverem fazendo barulho, eu não iniciarei a aula... Vamos fazer a correção dos exercícios substantivos compostos... Quem gostaria de colocar na lousa alguns substantivos compostos?"

Muitos alunos levantam as mãos.

Profa.: "Vamos, Cristina..."

A aluna foi ao quadro e escreveu a palavra "ALTO-FALANTE"; na seqüência outros substantivos compostos foram arrolados pelo grupo de alunos. Diante desses substantivos, a professora fez algumas perguntas:

Alunos: "O que fala alto..."

Profa. : "Vamos olhar no dicionário...Quem tem um dicionário?"

Profa. : "O que é alto-falante?"

Um aluno localiza num dicionário e levanta a mão.

Profa.: "Pode falar, Rafael."

Rafael: "Ampliador de som..."

Profa.: "A palavra, o substantivo composto arcoíris, o que significa? Quem já viu um arco-íris?"

Alunos: "Muitas vozes."

Profa. : "Como o arco-íris é formado?"

Alunos: "Pela chuva, pelo sol"... Muitas vozes.

Profa.: "O arco-íris é formado pela difração da luz nas pequenas gotinhas de água da chuva que ficam suspensas no ar depois da chuva... vamos consultá-la no dicionário? Francisco, você poderia procurar?"

Rafael passa o dicionário para Francisco, que teve um pouco de dificuldade para localizá-la. Pediu ajuda ao colega que estava a seu lado; os dois procuraram a palavra citada e, finalmente, Francisco encontrou-a e começou a ler.

Francisco: "Arco-íris substantivo masculino..."

Profa: "Muito bem, vamos passar para ..."

No episódio apresentado acima, o trabalho coletivo, o fazer junto, esteve em evidência. A professora permitiu a cooperação dos alunos com os colegas, incentivando-os a buscar novas informações. A gramática não é tratada como um conjunto de regras a serem seguidas, mas vinculada a outras situações vividas pela classe, sugerindo uma concepção que envolve o estudo da língua em seu funcionamento. Alguns conceitos tratados anteriormente evidenciam essa questão. Como já abordamos, Vygotsky revela a importância do trabalho coletivo, do falar, do ser ouvido, do trocar opiniões, enfim, de termos espaço para a construção individual e coletiva do conhecimento.

Vale pontuar, também, que as perguntas realizadas em sala, em sua maioria, eram abertas, pois procuravam investigar o que os alunos co- 
nheciam sobre determinado tema, trazendo informações novas.

As opiniões e respostas expressas pelos alunos mostraram que eles, de alguma forma, estavam reagindo à fala da professora. As perguntas colocadas visaram mais o desenvolvimento do raciocínio, incitando os alunos a observar, a pensar, a duvidar, a tomar partido, ao invés da busca de uma "única resposta possível". A palavra e a ação não foram exclusivas da professora e, embora ela não se valesse de uma conduta autoritária, não abriu mão de sua liderança, enfim, do seu papel de mediadora e promotora do conhecimento. Nesse sentido, posso afirmar que o discurso da professora era mais um, entre os muitos discursos que aconteciam na classe.

Outro aspecto interessante a ser mencionado diz respeito à disciplina em sala de aula. Observei, desde o início, que as regras estavam delimitadas; que os alunos permaneceram atentos, interessados e disciplinados. A aula não esteve tumultuada e não havia conversas paralelas; o ambiente estava bem organizado.

No entanto, vale comentar que não constatamos - com exceção da aula de História essa mesma organização nas outras disciplinas. Nelas, os alunos se mostraram indisciplinados, desinteressados ou desatentos. $\mathrm{O}$ fato de observar, num pequeno espaço de tempo, comportamentos tão diferentes de um mesmo aluno levou-me a cogitar que, na realidade, os alunos não eram indisciplinados, desinteressados ou desatentos; eles assim estavam em determinadas aulas. Suponho que esses momentos poderiam estar relacionados com as propostas de trabalho que estavam sendo realizadas.

\section{Algumas conclusões}

Uma das preocupações do presente trabalho foi verificar como as interações sociais estabelecidas no contexto de uma sala de aula da Escola "X"(Modular) poderiam influenciar no processo de ensino, considerando-se as formas de estruturação do tempo nessa mesma modalidade, em relação ao estabelecimento nas escolas denominadas Ensino Regular, que constituem a grande maioria da rede pública brasileira.

Os dados coletados mostraram que, apesar do Ensino Modular possibilitar ao professor uma maior concentração de tempo/dia letivo com o seu grupo, isso não garantiu que as interações (professor/aluno e aluno/aluno) fossem mais eficazes.

Pelo contrário, foi no contexto da sala de aula da Escola "Y"(Regular) que presenciei relações interpessoais mais adequadas ao processo de ensino - aprendizagem. Apesar de tempo menos concentrado, a professora manteve com seus alunos interações que propiciavam a construção do conhecimento, garantindo igualdade de oportunidades de expressão, possibilidades de participação e de interlocução. A professora assumiu o ensino de Língua Portuguesa dentro de uma visão interativa: a palavra e as ações não eram de sua exclusividade, sendo seu discurso apenas um entre os outros que a rodeavam.

Assim, posso afirmar que a interação estabelecida em sala de aula dependeu mais da competência, disponibilidade e da concepção de linguagem assumida pelas professoras do que de uma mudança na estrutura da escola e na organização do trabalho pedagógico.

A Proposta Modular, ao proporcionar um tempo mais concentrado para o trabalho em sala de aula, poderia possibilitar maior flexibilização e enriquecimento das atividades desenvolvidas em aula, caso o professor estivesse preparado para planejar e utilizar, com competência, o tempo de que dispõe no dia - a - dia do seu contato com a classe. Assim, diferentemente do que ocorre na Escola Regular, não haveria mais o "entra e sai" de professores com o conseqüente rompimento e fragmentação das tarefas que estão sendo realizadas.

Fazendo uma comparação entre os trabalhos desenvolvidos pelas professoras das Escolas Modular e Regular, o que garantiu resultados mais satisfatórios foi o fato da professora de Ensino Regular ter uma melhor formação, mais experiên- 
cia e, principalmente, ter assumido uma concepção de linguagem dentro de uma visão interativa. Independentemente da proposta que estava sendo aplicada, as observações realizadas na sala de aula do Ensino Regular revelaram que o trabalho de melhor qualidade aconteceu neste local.

O trabalho desenvolvido na sala de aula da Escola Modular nada teve de inovador. Aumentar/concentrar o tempo, sem que o professor tenha domínio de sua disciplina e encontre apoio na escola para se preparar, é inútil.
A análise dos dados parece mostrar que, antes de pensarmos em adotar determinada proposta, deveríamos considerar a formação dos docentes, suas condições de trabalho e a valorização de sua profissão. Qualquer projeto pedagógico precisa ser analisado e revisto pelo professor; sua participação é importante e necessária. De nada adiantam idéias fantásticas, "saídas" brilhantes, se não tivermos professores motivados, atuantes, e, principalmente, comprometidos com o seu trabalho.

\section{REFERÊNCIAS BIBLIOGRÁFICAS}

ANDRÉ, Marli Eliza D. A. de. Etnografia da Prática. Campinas, São Paulo: Papirus,1995.

AZENHA, Maria da Graça. Construtivismo de Piaget a Emilia Ferreiro. São Paulo: Ática, p. 17-33, 1994.

BAKHTIN, Mikhail. Marxismo e Filosofia da Linguagem. São Paulo: Hucitec, p. 48-66 e p. 110-127, 1995.

BRITTO, Luiz Percival Leme. Fugindo da norma. Campinas: Atomo, 1991.

CALKINS, Lucy McCormick - A arte de ensinar a Escrever - O desenvolvimento do discurso escrito - Porto Alegre: Artes Médicas, 1989.

CHARLOT, Bernard. Relação com o saber e com a escola entre estudantes de periferia. In: Caderno de Pesquisa, São Paulo,- no. 97, p. 47-63, maio, 1996.

CITELLI, Adilson Odair - O ensino de linguagem verbal: em torno do planejamento. In: Questões de Linguagem. Org. de Martins Helena Martins, São Paulo: Contexto, p. 11-17, 1991.

COLL, C.y SOLÉ, I. La interacción profesor alumno en el proceso de enseñanza y aprendizage. In:.... Desarrollo Psicológico y Educación,II. Madrid, Espanha: Alianza Editorial S.A., 1991.

DAVIS, Claudia, SILVA, Maria Alice Setúbal e ESPÓSITO, Yara. Papel e Valor das Interaçôes sociais em sala de aula. In: Caderno de Pesquisa, São Paulo (71) : 49-54 Nov. 1989.

DELAMONT, Sara. Interação na sala de aula. Lisboa, Portugal: Livros Horizonte, 1987. A pesquisa em sala de aula: uma crítica e uma nova abordagem. In: Patto, M.H.S. (org.). Introdução à psicologia escolar, 2a. ed. São Paulo: T.A. Queiroz, 1985,p.378-398.

DIETZSCH, Mary J. M. e SILVA, Maria A.S. Itinerantes e Itinerários na busca da palavra. In: Caderno de Pesquisa, São Paulo, no.88, p.55-63, Fevereiro, 1994.

FERREIRO, Emilia e TEBEROSKY, Ana. Psicogênese da língua escrita. Porto Alegre: Artes Médicas, 1991.

GERALDI, J.W. . Concepçôes de Linguagem e Ensino da Língua. In: GERALDI, J.W.,(Org). O Texto na sala de aula. Cascavel, Paraná: Assoeste/UNICAMP 1984.

. Portos de passagem: linguagem, trabalho e ensino. São Paulo: Martins Fontes, 1991.

GUDSDORF, Georges. Professores para quê ?. São Paulo: Martins Fontes, 1987.

HUTMACHER, W. A escola em todos os seus estados: das políticas de sistema às estratégias de estabelecimento. In.: Nóvoa, A ., (org.). As organizações escolares em análise. Lisboa: Dom Quixote, 1995, p. 47-76.

JOBIN, S. e kramer, S. . O debate Piaget/Vygotsky e as políticas educacionais. In: Cadernos de Pesquisa, São Paulo: n.77, p.69. 80, Maio, 1991.

KLEIMAN, Angela B.. Leitura: ensino e pesquisa. São Paulo: Pontes,1989.

LAJOLO, M. . O textonnão é pretexto . In: ZILBERMAN, Regina (org.)Leitura em crise na escola. Porto Alegre: Mercado Aberto, 1993, p.51-62.

. Do mundo da leitura para a leitura do mundo. São Paulo: Ática S. A. , 1994.

LEITE, Lígia Chiappini M. e MARQUES, Regina M.H.. Ao pé do texto na sala de aula. In: ZILBERMAN, Regina (org.). Leitura em crise na escola Porto Alegre: Mercado Aberto, 1993, p.37-49.

LEONTIEV, A .. Os princípios do desenvolvimento mental e o problema do atraso mental. In.: LEONTIEV, A ., VYGOTSKY, LURIA, A. R. e outros. Psicologia e Pedagogia. São Paulo: Moraes, 1991, p. 59-76.

LIBÂNEO, José Carlos. Didática. São Paulo: Cortez, 1994, p.195-220.

LINO, Macedo. Ensaios Construtivistas. São Paulo: Casa do psicólogo, 1994, p. 63-79. 
LOPES, Harry Vieira. A prática do português no 1o. grau: objetivos, conteúdos, metodologia e avaliação. In: Murrie, Zuleika de Felice (org.). Universos da palavra. São Paulo: Iglu, 1995, p.95-167.

LUCKESI, Cipriano Carlos. Subsídios para a organização do trabalho docente. In: Revista Idéias no.11, FDE., 1991, p.88-103.

MARTINS, M. H.. O que é leitura. São Paulo: Brasiliense, 1996.

MASETTO, Marcos. Didática: a aula com o centro. São Paulo: FTD, 1994, p.76-83.

MURRIE, Zuleika de F. . (org.). O ensino de português do primeiro grau à Universidade. São Paulo: Ensino Contexto, 1992.

NÓVOA, A . Formação de professores e profissão docente. In.: Nóvoa, A . (org.) Os professores e sua formação. Lisboa: Dom Quixote, 1992, p. 15-33.

. Para uma análise das instituições escolares. In.: Nóvoa, A . (org.). As organizações escolares em análise. Lisboa: Dom Quixote, 1995, p. 13-43.

. Os professores e suas histórias de vida. In.: Nóvoa. A. (org). Vidas de professores. Porto: Porto, 1995, p. 11-25.

OLIVEIRA, M. K. de . Vygotsky : Aprendizado e desenvolvimento processo sócio-histórico. São Paulo: Scipione, 1993.

PIMENTA, Selma Garrido. Questões sobre a organização do trabalho na Escola. In: Revista Idéias n. 16, FDE, São Paulo: p.78-83.

PINO, Angel - O Conceito de Mediação Semiótica em Vygotsky e seu papel na explicação do Psiquismo Humano. Cadernos Cedes Campinas 24 - Pensamento e Linguagem Est. na perspectiva da Psicologia Soviética Março 1991 - pag. 32-43

SALES, Maria Rita N. O.. A sala de aula como objeto de análise na área da didática. In: SALES, Maria Rita N. O., org. Didática : Ruptura, Compromisso e Pesquisa. Campinas, São Paulo: Papirus, 1993, p. 35-62.

SANTOS, Wladir. Ensino Modular - Uma resolução brasileira na educação. Campinas: Edilap, 1994.

SÃO PAULO (Estado) Secretaria de Educação - Coordenadoria de Estudos e Normas Pedagógicas. Proposta Curricular para o ensino de língua portuguesa para o 1o. grau. São Paulo: SE/CENP, 1991.

Estudo Avaliatório das Unidades Escolares da Rede Estadual de Ensino com Organização Didático-Pedagógica estru tura em Módulos. São Paulo, SE/CENP, 1994.

SILVA, Lilian L. M. da. (org.). O ensino de Língua Portuguesa no primeiro grau. São Paulo: Atual, 1986.

TENCA, Sueli Cotrim. O ensino através de módulos na escola-padrão JoãoXXIII: estudo e acompanhamento de um projeto em implantação. São Paulo: SE/CENP, 1994.

TRAVAGLIA, Luiz Carlos. Gramática e interação: uma construção possível. Campinas: Papirus, 1995, p. 11-35.

VEIGA, I. P. A .. Projeto Político-pedagógico da escola-uma construção possível. Campinas: Papirus, 1995, p. 11-35.

VIEIRA, Yara F. Recepção ativa de textos: uma forma de diálogo. In.: Subsídios à proposta Curricular de Língua Portuguesa para o 1o. e 2 o grau. São Paulo: 3 vol., SE/CENP, 1988.

VIGNER, Gerald.. Intertextualidade, norma e legibilidade. In: GALVES, C. O texto, leitura e escrita. Campinas: Pontes, 1988.

YGOTSKY,L.S. A Formação Social da Mente - São Paulo: Martins Fontes 1994. . Pensamento e Linguagem - São Paulo: Martins Fontes, 1995. 